\title{
Electroencephalographic and Plasma Electrolyte Changes after Cardiac Surgery in Children
}

\author{
ANN HARDEN,* PH.D. ; G. H. GLASER,*† M.D. ; G. PAMPIGLIONE,* M.D., M.R.C.P.
}

Brit. med f., 1968, 4, 210-213

\begin{abstract}
Cummary: Serial electroencephalographic studies were carried out during the first few days following open heart surgery in 53 children who had an uneventful surgical procedure and postoperative recovery. While the E.E.G. taken a few hours after the end of the operation was comparable to the preoperative one, an increase in slow activity subsequently occurred in all patients and reached its maximum on the first or second postoperative day. This increase in slow activity was not commonly associated with any obvious altered state of consciousness and the preoperative E.E.G. patterns reappeared within one week. A fall in plasma sodium level with a comparable fall in plasma chloride usually occurred around the second postoperative day, returning to the preoperative levels by the fourth postoperative day.

It is suggested that both events are part of a normal reversible physiological response to the operative trauma. The presence of generalized slow activity in the E.E.G. in the first few days after heart surgery does not necessarily imply that there has been cerebral damage from anoxia.
\end{abstract}

\section{Introduction}

The electroencephalogram has often been used as a monitor of cerebral function in patients undergoing cardiac surgery, because of the various complications that may occur during and following these procedures. At the Hospital for Sick Children since 1957 E.E.G. studies have been made before, during, and after heart surgery. In addition to E.E.G. changes due to circulatory complications during the operation it was found that reversible E.E.G. changes commonly occurred in the postoperative phase, usually concomitant with transient metabolic alterations, particularly a fall in plasma sodium levels (Pampiglione, 1965).

The present study was planned prospectively and is concerned with the cycle of some physiological events following uncomplicated cardiac surgery in children. Particular attention was devoted to the timing, severity, and reversibility of the E.E.G. changes, the plasma electrolyte values, and the patient's state of consciousness during the first postoperative week.

\section{Materials and Methods}

From a total of 122 children on whom serial E.E.G. and metabolic investigations were carried out in relation to cardiac surgery, 53 were selected for the present study. This group included only those children who experienced no marked hypotensive or hypoxic episodes during or after surgery, those who did not require post-

\footnotetext{
* Department of Clinical Neurophysiology, the Hospital for Sick Children, Great Ormond Street, London W.C.1.

tPresent address: Division of Neurology, Yale University School of Medicine, New Haven, Connecticut, U.S.A.
}

operative mechanical ventilation, and those who showed no evidence of neurological complications and no signs of cardiac, renal, or liver failure. All the 53 children of this group had congenital heart disease, and open heart surgery was carried out with the use of cardiopulmonary bypass in most cases but sometimes under hypothermia.

The children were aged 4 to 14 years and were divided into the following three groups in order to recognize any peculiarity that might be related to age and cerebral maturation: group 1 (4-6 years) 16 cases, group 2 (7-9 years) 16 cases, and group 3 (1014 years) 21 cases.

E.E.G.s were taken before the surgical intervention in all cases and during the surgical procedure in most of them. After surgery 4 to 10 E.E.G.s were taken at the patient's bedside at selected time intervals: (1) at least one E.E.G. a few hours after the end of the operation (operative day), (2) one or more records on the day after the operation (first postoperative day), (3) one or more records two days after the operation (second postoperative day), (4) one or more records three or four days after the operation (third or fourth postoperative day), and (5) in some cases further records up to two to three weeks after the operation.

Nine silver silver-chloride disc electrodes were stuck to the scalp before the operation in standard positions according to measurements from bony landmarks (Pampiglione, 1956). Contact was made through a saline jelly and the contact resistance lowered to less than $5 \mathrm{k} \Omega$. A portable eight-channel apparatus (Offner Type $T$ ) was used-seven channels recording the E.E.G. and one channel recording an electrocardiogram (modified lead I). For the E.E.G. an amplification of $10 \mu \mathrm{V} / \mathrm{mm}$. pen deflection was used (the gain being reduced on occasion), the time constant was $0.3 \mathrm{sec}$., and the high-frequency response was linear within $10 \%$ to $70 \mathrm{c} . / \mathrm{sec}$. (H.F. cuts were employed when necessary).

From capillary or arterial blood samples estimations of plasma sodium, potassium, and chloride were carried out by standard methods. This was done preoperatively, and two to five estimations were also made from the first to the fifth postoperative day. The blood sample on each occasion was taken as near as possible to the time of the E.E.G. There was considerable difficulty in assessing precisely the child's state of consciousness in the postoperative period because detailed neurological and mental examination was not feasible at this time. It was therefore agreed that only a rather broad assessment should be made at the time of each E.E.G. to describe the child as being (a) awake and alert, (b) drowsy or asleep but rousable, or $(c)$ unrousable.

\section{Results}

In most cases the E.E.G. taken a few hours after the end of the operation showed some excess of low-amplitude fast activities (probably related to the recent administration of anaesthetics), but there was usually no excess of slow components. In a number of cases the patient was rousable and able to open and close his eyes to command. The rhythmic activity recorded from the posterior regions of the head was of comparable frequency to that seen in the preoperative tracing and was usually altered by eye opening. However, over the next day or two some E.E.G. changes gradually appeared in all 53 patients (see Fig. 1). These changes usually consisted in an 


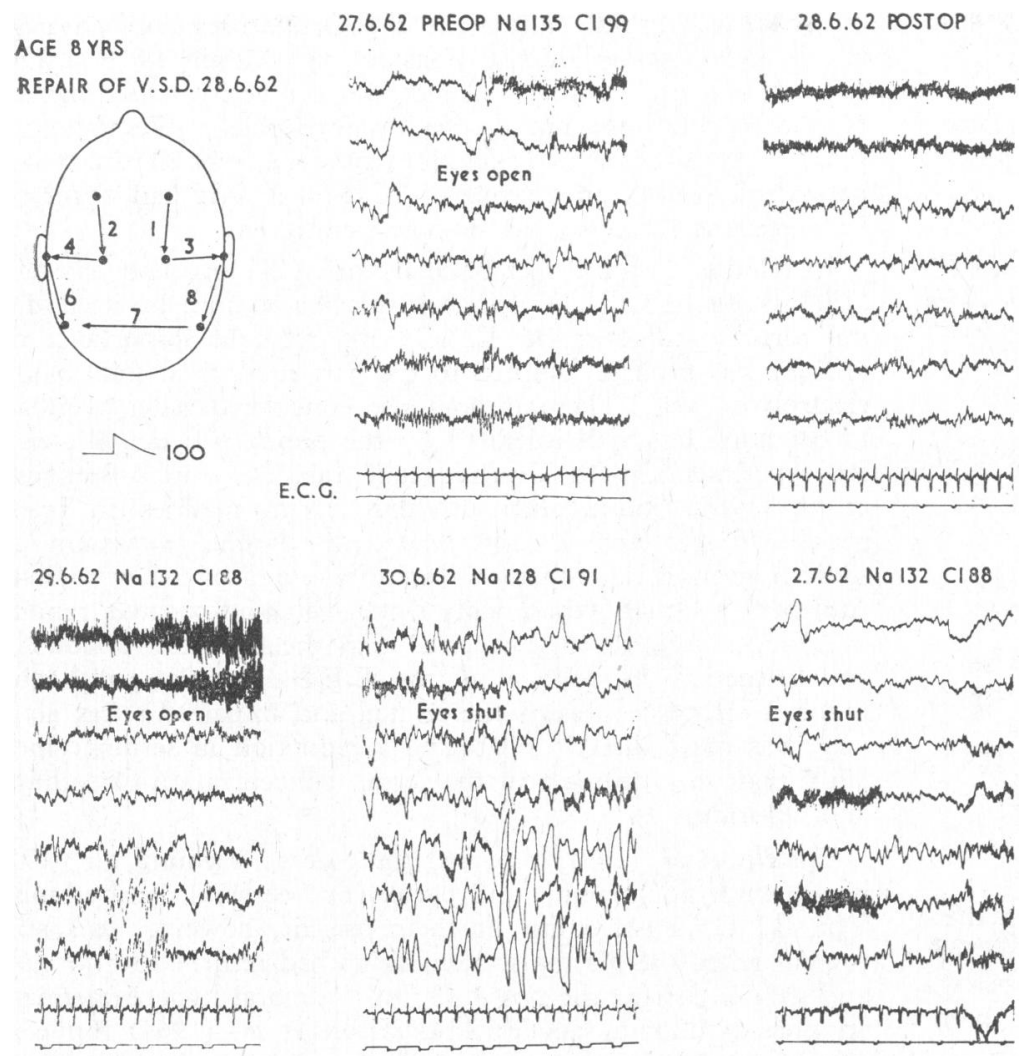

Fig. 1.-Case 1. On the second postoperative day (30 June 1962) the patient showed a peak E.E.G. change of moderate degree and a mild fall in plasma sodium to 128 $\mathrm{mEq} / \mathrm{l}$. He was awake and alert.

increase in slow activity over the posterior temporal regions particularly after eye closure. This slow activity often became generalized, with 1-2 c./sec. components which increased in amplitude, sometimes reaching well over $0.5 \mathrm{mV}$. When the patient was alert eye opening was often followed by a diminution in the amount and amplitude of all slow activities, which tended to fluctuate somewhat, but nearly always increased after either voluntary or passive eye closure. After the third to fifth postoperative day the slow activity gradually decreased and the E.E.G. returned to the preoperative pattern within one week after surgery. In each patient's series one E.E.G. was selected which showed the maximum amount and amplitude of slow activity ("peak E.E.G. change"). These records were divided into one of three groups having predominantly (1) mild (4-5 c./sec. of 100-200 $\mu \mathrm{V}$ ), (2) moderate $(2-3 \mathrm{c} . / \mathrm{sec}$. of $200-300 \mu \mathrm{V})$, or (3) marked $(0.5-1.5 \mathrm{c}$. $/ \mathrm{sec}$. of $400-500 \mu \mathrm{V})$ changes at that time (see Table I). While only four children

TABLE I.-Severity of Peak E.E.G. Change

\begin{tabular}{|c|c|c|c|c|c|}
\hline Group & None & $\begin{array}{c}\text { Mild } \\
4 \mathrm{c} . / \mathrm{sec} . \\
100-200 \mu \mathrm{V} \\
\end{array}$ & $\begin{array}{c}\text { Moderate } \\
2-3 \text { c./sec. } \\
200-300 \mu \mathrm{V}\end{array}$ & $\begin{array}{c}\text { Marked } \\
0.5-1.5 \mathrm{c} . / \mathrm{sec} . \\
400-500 \mu \mathrm{V}\end{array}$ & Total \\
\hline $\begin{array}{l}1 \text { (age 4-6) } \\
2 \text { (age 7-9) } \\
3 \text { (age 10-14) }\end{array}$ & $\begin{array}{l}0 \\
0 \\
0 \\
0\end{array}$ & $\begin{array}{l}0 \\
2 \\
2\end{array}$ & $\begin{array}{l}3 \\
6 \\
7\end{array}$ & $\begin{array}{r}13 \\
8 \\
12\end{array}$ & $\begin{array}{l}16 \\
16 \\
21\end{array}$ \\
\hline Total & 0 & 4 & 16 & 33 & 53 \\
\hline
\end{tabular}

showed mild E.E.G. changes, most patients (33) showed marked changes, which were proportionally slightly more noticeable in the youngest age group (13 out of 16 of those under 7 years). In 10 patients the peak E.E.G. change occurred as early as the morning of the first postoperative day, while in 15 it was seen in the evening of the first postoperative day, but more usually it was seen on the second postoperative day ( 28 children).
Small doses of morphine were routinely administered postoperatively but no other sedation was given. The patient's state of consciousness at the time of each E.E.G. was broadly assessed. When the patient was not awake attempts were made to rouse him and persuade him to open and close his eyes to command, and the assessment of the E.E.G features included the changes elicited by such stimuli. Of the 53 patients 29 were in fact awake and alert at the time of the peak E.E.G. change, 22 were drowsy or asleep but rousable, and only two were not rousable (see Table II). The severity of the peak E.E.G. change did not appear to bear any direct relation to the state of consciousness at the time as shown in Table II. The two unrousable patients did show marked E.E.G. changes, but changes of similar severity were also seen in 16 of the 29 children who were awake and alert and in 15 children who, though drowsy or asleep, were rousable.

The plasma electrolyte mean values in the group of 53 children were plotted with mean deviations (see Fig. 2). The plasma sodium fell from a mean value of $139.5 \mathrm{mEq} / 1$. preoperatively to $132.5 \mathrm{mEq} / 1$. on the first postoperative day, reaching its lowest value of $130.5 \mathrm{mEq} / 1$. on the second postoperative day. The mean value of plasma chloride also showed a similar trend, falling from $99.5 \mathrm{mEq} / 1$. preoperatively to $91.0 \mathrm{mEq} / 1$. on the second postoperative day.

Both the sodium and the chloride had returned to more normal values by the fourth postoperative day. The values of plasma potassium were much more variable, as can be seen by the wide mean deviations. Though the mean plasma potassium value rose postoperatively, varying degrees of haemolysis had occurred in most of the blood samples, resulting in spurious levels.

TABLE II.-State of Consciousness in Relation to Peak E.E.G. Change

\begin{tabular}{|c|c|c|c|c|c|}
\hline \multicolumn{2}{|c|}{ E.E.G. Change } & $\begin{array}{c}\text { Alert } \\
\text { and } \\
\text { Antre }\end{array}$ & $\begin{array}{l}\text { Drowsy, } \\
\text { Asleep but }\end{array}$ & $\begin{array}{c}\text { Not } \\
\text { Rousable }\end{array}$ & Total \\
\hline $\begin{array}{l}\text { Mild .. } \\
\text { Moderate } \\
\text { Marked .. }\end{array}$ & $\begin{array}{l}. \\
\because \\
\because\end{array}$ & $\begin{array}{l}1 \\
12 \\
16\end{array}$ & $\begin{array}{r}3 \\
4 \\
15\end{array}$ & $\begin{array}{l}0 \\
0 \\
2\end{array}$ & $\begin{array}{r}4 \\
16 \\
33\end{array}$ \\
\hline Total & .. & 29 & 22 & 2 & 53 \\
\hline
\end{tabular}

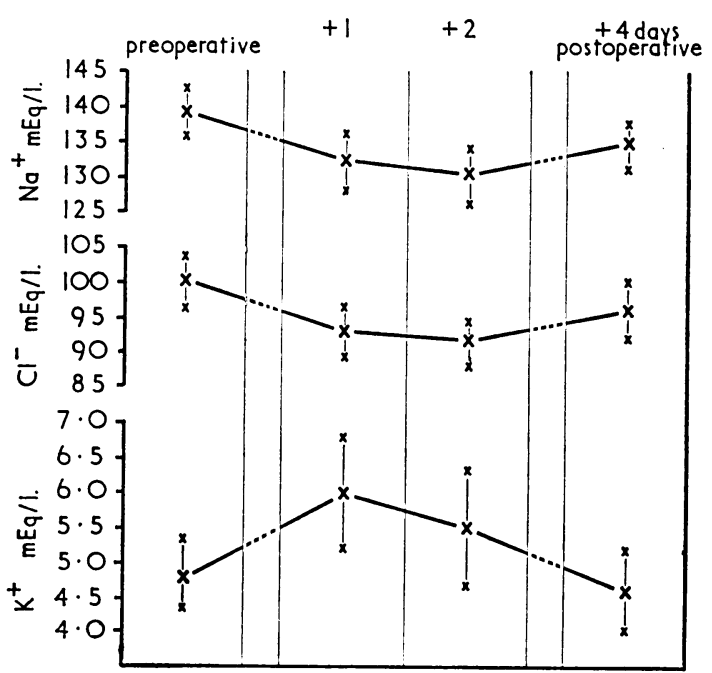

FIG. 2.-Mean values of plasma electrolytes (with mean Fig. 2.- Mean values of plasma electrolytes (with mean
deviations) preoperatively and postoperatively in 53 patients. 
The severity of the peak E.E.G. change was compared with the severity of the fall in plasma sodium values (slight fall, 5$10 \mathrm{mEq} / \mathrm{l}$. ; marked fall, $10-20+\mathrm{mEq} / 1$.) in each patient (see Table III): 21 of the 31 patients with marked E.E.G. alterations also had a marked fall in plasma sodium. In the 20 patients with either moderate or mild peak E.E.G. change marked or slight falls in plasma sodium occurred about equally. In the remaining two children there was an unexpected increase in plasma sodium, though the usual fall in plasma chloride occurred at the appropriate time as well as a marked peak E.E.G. change. Twenty-three patients showed peak E.E.G.

Table III.-Severity of Peak E.E.G. Change in Relation to Degree of Sodium Fall

\begin{tabular}{|c|c|c|c|c|c|c|c|}
\hline \multirow{2}{*}{ Group } & \multicolumn{2}{|c|}{$\begin{array}{l}\text { Marked } \\
\text { E.E.G. Change }\end{array}$} & \multicolumn{2}{|c|}{$\begin{array}{c}\text { Moderate } \\
\text { E.E.G. Change }\end{array}$} & \multicolumn{2}{|c|}{$\begin{array}{l}\text { Mild } \\
\text { E.E.G. Change }\end{array}$} & \multirow{2}{*}{ Total } \\
\hline & $\begin{array}{l}\text { Marked } \\
\mathrm{Na} \text { Fall }\end{array}$ & $\begin{array}{l}\text { Slight } \\
\text { Na Fall }\end{array}$ & $\begin{array}{l}\text { Marked } \\
\text { Na Fall }\end{array}$ & $\begin{array}{l}\text { Slight } \\
\text { Na Fall }\end{array}$ & $\begin{array}{l}\text { Marked } \\
\text { Na Fall }\end{array}$ & $\begin{array}{l}\text { Slight } \\
\text { Na Fall }\end{array}$ & \\
\hline $\begin{array}{l}1 \\
2 \\
3\end{array}$ & $\begin{array}{r}11 \\
5 \\
5\end{array}$ & $\begin{array}{l}1 \\
3 \\
6\end{array}$ & $\begin{array}{l}2 \\
3 \\
4\end{array}$ & $\begin{array}{l}1 \\
3 \\
3\end{array}$ & $\begin{array}{l}0 \\
0 \\
2\end{array}$ & $\begin{array}{l}0 \\
2 \\
0\end{array}$ & $\begin{array}{l}15^{*} \\
16 \\
20^{\circ}\end{array}$ \\
\hline Total & 21 & 10 & 9 & 7 & 2 & 2 & 51 \\
\hline
\end{tabular}

Slight $\mathrm{Na}$ fall $=5-10 \mathrm{mEq} / \mathrm{l}$. Marked $\mathrm{Na}$ fall $=10-20+\mathrm{mEq} / \mathrm{l}$.
*ne patient with peak E.E.G. change associated with sodium rise.

change on the same day as the lowest sodium value, whether this was on the first or second postoperative day. In 28 children the peak E.E.G. change was seen either the day before (13) or the day after (15) the lowest sodium value had been reached.

The following case is included to illustrate the sequence of events that commonly occurred.

\section{Case 1 (see Fig. 1)}

This boy was 8 years old when surgery was carried out on cardiopulmonary bypass for repair of a ventricular septal defect. Before surgery the plasma sodium was $135 \mathrm{mEq} / \mathrm{l}$. and the E.E.G. showed some alpha rhythm, mixed with some slower components, fairly symmetrical and blocked on eye opening. The E.E.G. taken a few hours after the repair of the septal defect was not substantially different from the preoperative one.

By the first postoperative morning there had been an increase in 4-7 c./sec. activity following eye closure. At this time there was a slight fall of plasma sodium to $132 \mathrm{mEq} / \mathrm{l}$. On the second postoperative day, though the child was alert, 1-4 c./sec. activity was prominent, of higher amplitude posteriorly than anteriorly, increasing after eye closure, and sometimes reaching $400 \mu \mathrm{V}$. At this time the plasma sodium had fallen to $128 \mathrm{mEq} / \mathrm{l}$. By the fourth postoperative day the slow activity had almost disappeared, though the E.E.G. had not completely returned to the preoperative pattern, there still being some excess of 4-7 c./sec. components mixed with an unstable alpha rhythm. The plasma sodium had not quite returned to preoperative levels, being still $132 \mathrm{mEq} / \mathrm{l}$.

There was a peak E.E.G. change of moderate degree on the second postoperative day. The preoperative plasma sodium was $135 \mathrm{mEq} / \mathrm{l}$. (in the lower range of normality for this group of children). Though it fell only $7 \mathrm{mEq} / \mathrm{l}$. postoperatively (slight sodium fall) it did actually reach the relatively low value of 128 $\mathrm{mEq} / \mathrm{l}$. This sodium fall occurred on the same day as the peak E.E.G. change. The patient's state of consciousness was not substantially depressed, and he remained awake and alert throughout.

\section{Discussion}

The morphology of the electrical activity of the brain as recorded in the E.E.G. is largely dependent on cerebral metabolic conditions. In particular acute anoxia (either respiratory or ischaemic) rapidly alters the E.E.G. features both in man and in experimental animals (Gastaut and Meyer, 1961). The severity of this change is related to the severity and duration of anoxia, and may not be readily reversible. We therefore thought it essential to exclude from the present study all patients in whom an episode of cerebral anoxia had occurred either during the operation or postoperatively.

In relation to other metabolic factors, Cadilhac and Ribstein (1961) suggested that a change in plasma sodium by itself did not directly influence the E.E.G., and that the importance of sodium was probably limited to the part it plays in total blood electrolyte level. These authors also considered water overload to be much less well tolerated by the brain than dehydration. In experiments with overhydrated rabbits, Funck-Brentano et al. (1960) found that although " abnormalities in brain activity" were not directly related to plasma potassium or sodium levels E.E.G. changes "were favoured by a low sodium content." Other experiments with water-intoxicated rabbits by Dodge et al. (1960) suggested that the progressive slowing and reduction in voltage of the E.E.G., together with the reduced responsiveness of the animal and impaired reflex activity, was more directly related to a reduction in serum osmolality than to a decrease in the serum concentration of sodium and chloride.

Epstein et al. (1961) reported the case of a young girl with persistent hyponatraemia and paroxysmal cerebral dysrhythmia. The E.E.G. abnormality in their patient, however, was still present when the plasma sodium 'value had returned to normal, and they suggested the possibility of "cerebral hyponatraemia." In normal human females Margerison et al. (1964) found a significant association between changes in mean abundancies of 7,8 , and $9 \mathrm{c} . / \mathrm{sec}$. activity in the E.E.G. and changes in plasma sodium in relation to the subject's menstrual cycle.

In our series of 53 children the postoperative alterations of plasma electrolytes, though not always parallel to the E.E.G. changes, tended to coincide with the peak E.E.G. changes, and would seem to be part of the same physiological response to the operative trauma. Usually the plasma electrolyte values returned to more normal values a day or two before the E.E.G. returned to the preoperative patterns.

Gross falls in plasma sodium levels to values below 118 $\mathrm{mEq} / \mathrm{l}$. have been reported by Leaf and Roth (1965) with some alterations in consciousness, but such low values were not encountered in our series. It should be emphasized that in our material, in spite of the considerable excess of high-amplitude slow activity at peak E.E.G. change, the patients usually remained alert.

It is well known that general transitory biochemical changes, including altered plasma electrolyte values, may follow various operative procedures. Detailed metabolic balance studies on a few adult patients have been carried out by some workers (Moore, 1953; Wilson et al., 1954). The fall in plasma sodium which commonly occurs in the first few days postoperatively appears to be greater after cardiac surgery than after other traumatic procedures. This postoperative hyponatraemia has been attributed by some authors solely to water retention related to altered secretion of antidiuretic hormone (Aronstam et al., 1953 ; Goodyer and Glenn, 1955 ; D'Angelo et al., 1958). The mechanism underlying the hyponatraemia, however, is obscure, and Wilson (1959) suggested that, as well as antidiuretic hormone, altered secretion of adrenocortical hormones, especially aldosterone, may also be implicated in this postoperative electrolyte disturbance.

The cause of these electrolyte changes, as yet unknown, might also determine the alterations of cerebral electrical activity. However, since sodium and potassium play such an important part in controlling the membrane potential of nerve cells, it would be surprising if the altered plasma electrolyte values (or any change in osmolality they represent) did not have some 
effect on cerebral electrogenesis. The relation between plasma electrolyte changes and increase in slow activity in the E.E.G. showed some individual variations, but we were not able to measure total body or urinary electrolyte values, osmolality of plasma or urine, or the rate at which these metabolic disturbances evolved. Differences in intravenous fluids given ( $5 \%$ dextrose, 0.09 or $0.18 \% \mathrm{NaCl} /$ dextrose solution) did not affect substantially the general cycle of events. Neither the patient's age nor the type of operation appeared to influence the degree or the timing of the postoperative metabolic and E.E.G. changes.

In conclusion, it has been our experience that a generalized increase in slow activity in the E.E.G. occurs between the first and the fourth day after heart surgery. The E.E.G. changes are fully reversible, in contrast to the effects of severe cerebral anoxia. The clinical evaluation of an excess of slow activity in the E.E.G. after cardiac surgery should take into account the patient's metabolic state, and particularly alterations of plasma electrolytes with hyponatraemia.

This work was aided in part by grants from the Commonwealth Fund and the United Health Foundations (G. H. G.) and the Joint Research Board, the Hospital for Sick Children, London (A. H.). We wish to express our thanks to the staff of the thoracic unit and the department of chemical pathology, the Hospital for Sick Children.

\section{REFERENCES}

Aronstam, E. M., Schmidt, C. H., and Jenkins, E. (1953). Ann. Surg., $137,316$.

Cadilhac, J., and Ribstein, M. (1961). Wld Neurol., 2, 296.

D'Angelo, G. J., Murdaugh, H. V., and Sealy, W. C. (1958). Surg. Gynec. Obstet., 106, 87.

Dodge, P. R., Crawford, J. D., and Probst, J. H. (1960). Arch. Neurol., 3, 513 .

Epstein, F. H., Levitin, H., Glaser, G., and Lavietes, P. (1961). New Engl. F. Med., 265, 513 .

Funck-Brentano, J. L., Lossky-Nekhorocheff, I., and Altman, J. (1960). Electroenceph. clin. Neurophysiol., 12, 185.

Gastaut, H., and Meyer, J. S. (Editors) (1961). Cerebral Anoxia, and the Electroencephalogram. Springfield, Illinois.

Goodyer, A. V. N., and Glenn, W. W. L. (1955). Circulation, 11, 584.

Leaf, A., and Roth, S. I. (1965). New Engl. 7. Med., 273, 1039.

Margerison, J. H., Anderson, W. McC., and Dawson, J. (1964). Electroenceph. clin. Neurophysiol., 17, 540 .

Moore, F. D. (1953). Ann. Surg., 137, 289.

Pampiglione, G. (1956). Proc. electrophysiol. Technol. Ass., 7, No. 1, p. 20 .

Pampiglione, G. (1965). Lancet, 2, 263.

Wilson, G. M. (1959). In Clinical Effects of Electrolyte Disturbances, edited by E. J. Ross, p. 194. London.

Wilson, G. M., Edelman, I. S., Brooks, L., Myrden, J. A., Harken, D. E., and Moore, F. D. (1954). Circulation, 9, 199.

\title{
Chromosomes and Transformation of Lymphocytes in Lymphoproliferative Disorders
}

\author{
SYLVIA D. LAWLER,* M.D., M.C.PATH.; C. R. PENTYCROSS, † M.B., B.CH. ; B. R. REEVES, $\ddagger$ B.SC.
}

Summary : In chronic lymphocytic leukaemia the $\checkmark$ majority of circulating lymphocytes which responded to phytohaemagglutinin in vitro were found to have normal karyotypes. A minor population of cells in patients treated with chemotherapy had an increased number of chromosomal rearrangements as compared with cells from normal controls and untreated patients with chronic lymphocytic leukaemia. Probably bonemarrow and lymph-node cells also had a normal karyotype.

In the other lymphoproliferative disorders the peripheral blood lymphocytes had either normal karyotypes or chromosomal abnormalities attributable to treatment, even in those cases where the tumour cells of involved lymph nodes were known to have abnormal karyotypes.

It was possible that circulating tumour cells were present in one case.

- Senior Lecturer.

† Leukaemia Research Fellow.

\# Research Assistant.

Department of Clinical Research, Royal Marsden Hospital and Institute of Cancer Research, London S.W.3.

\section{Introduction}

In the lymphoproliferative disorders specific chromosomal abnormalities of the circulating lymphocytes have not been reported (Fitzgerald and Adams, 1965). An inherited constitutional abnormality, involving a deletion of the short arm of a group $\mathrm{G}$ chromosome, has been described in several members of a family, two of whom developed chronic lymphocytic leukaemia (Gunz et al., 1962). Since transmissible morphological variants of chromosomes are found in normal individuals such an association could be fortuitous. In subsequent cytogenetic studies of 11 other families with leukaemic sibs no further inherited chromosomal abnormalities have been observed (Fitzgerald et al., 1966). On the other hand, Goh (1967), exploiting the fact that the yield of mitoses is increased in lymphocyte cultures from patients with chronic lymphocytic leukaemia if the culture time is prolonged beyond the usual three days, claimed that even in untreated patients $40 \%$ of the karyotypes of cells with 46 chromosomes were rearranged (pseudodiploid).

This paper records the results of chromosome studies on the peripheral blood lymphocytes of patients with chronic lymphocytic leukaemia and other lymphoproliferative disorders, and on a series of normal controls. In most instances the lymphocytes 